\title{
Clinical profile and outcome of neonates admitted to the Neonatal Care Unit at a teaching hospital in Lalitpur, Nepal
}

\section{Shakya A', Shrestha $D^{2}$, Shakya H³ , Shah $\mathrm{SC}^{4}$, Dhakal AK ${ }^{5}$}

${ }^{1}$ Arati Shakya, Lecturer; ${ }^{2}$ Devendra Shrestha, Associate Professor; ${ }^{3}$ Henish Shakya, Lecturer; ${ }^{4}$ Subhash Chandra Shah, Lecturer; ${ }^{5}$ Ajaya Kumar Dhakal, Lecturer; Department of Paediatrics, KIST Medical College Teaching Hospital, Lalitpur, Nepal.

\section{ABSTRACT}

Background: Neonatal period is a vulnerable time in which the newborn has to adapt to a totally new environment and is susceptible to many problems, which may even be life threatening. It is found that neonatal mortality rate is decreasing in Nepal but at a slower pace than infant and child mortality. In order to improve neonatal outcome, it is crucial to identify the areas where health care can be improved.

Objectives: This study was conducted to analyze the spectrum of diseases and outcomes at a level two NICU at a tertiary care teaching hospital.

Methods: A descriptive observational study conducted at the neonatal care unit in the Department of Paediatrics at KIST Medical College, Lalitpur, Nepal over one year from 14th of April 2013 to 13th April 2014. Data on age at admission, gender, gestational age, birth weight, initial presenting symptoms at admission, final diagnosis and outcome were collected from in patient records at the hospital record section and analyzed using SPSS 17.0.

Results: A total of 279 neonates were studied. The commonest causes of admission were infection (45.9\%), followed by respiratory conditions (14.7\%), neonatal jaundice (12.5\%), perinatal asphyxia (9.3\%) and prematurity/ small for gestational age (SGA) (6.5 \%). Most of the admissions (62\%) were during the first 24 hours of life. The majorities, 89.2\%, were term gestation and $10.8 \%$ were preterm. Most of the preterm babies were late preterms with gestational ages between $35-$ 36 weeks (73\% of preterms were late preterms). Total of four mortalities (1.4\%) occurred, three of which were due to perinatal asphyxia and one was a Down's syndrome with overwhelming sepsis.

Conclusion: In this study, infections followed by respiratory conditions were the leading causes of admission. Most of the admissions occurred during the first 24 hours of life. This emphasizes the fact that attentiveness during the first day of life, simple measure to prevent infection and early detection and treatment may go a long way in improving neonatal outcome.

Key words: Neonate, Neonatal mortality rate, Outcome

\section{INTRODUCTION}

T. the neonatal period, consisting of the first 28 days of life, is a crucial time period in which the newborn undergoes considerable changes in order to adjust from a totally dependent in utero existence to a fully independent ex utero life. It is in this span of time that a neonate is most susceptible to problems that may range from mild to life threatening and which are responsible for maximum morbidity and mortality.

Address for correspondence

Dr Arati Shakya

Lecturer

Department of Paediatrics

KIST Medical College Teaching Hospital, Lalitpur, Nepal

E-mail:dr_rtshakya@hotmail.com
The Nepal Demographic and Health Survey of 2011 found under five mortality rate of 54/1000 live births, infant mortality rate of $46 / 1000$ live births and neonatal mortality rate of 33/1000 live births ${ }^{1}$. When data over the last 15 years were analyzed, it was found that neonatal mortality has decreased but at a slower pace than infant and child mortality'. This result highlighted that a greater proportion of childhood mortality is now due to neonatal deaths. There is a pressing need to explore the reason for the slow decline in neonatal mortality rate which will help to develop and implement strategies to decrease the number of neonatal deaths.

Most of the causes of morbidity and mortality in the neonatal period are preventable by good antenatal 
care and early detection and treatment. These treatable causes vary from place to place and even from time to time in a particular place ${ }^{2}$. Previous studies done in Nepal have diverse results with sepsis, perinatal asphyxia, prematurity and neonatal jaundice being the commonest causes of admission ${ }^{3-5}$. This study was undertaken with the objective to determine the spectrum of neonatal diseases and its outcome in a level two Neonatal Intensive Care Unit (NICU) at a teaching hospital in Lalitpur, Nepal.

\section{METHODS}

This was a descriptive observational study conducted at the neonatal care unit in the department of Paediatrics at KIST Medical College, Lalitpur, Nepal. The neonatal care unit consisted of a level two NICU, equipped with radiant warmers and phototherapy units, and a step down nursery. The study was carried out over a period of one year from 14th of April 2013 to 13th April 2014. All newborns (both inborn and out-born) who were admitted during this time were included. Data was collected from the in patient records at the hospital record section. Data on age at admission, gender, gestational age, birth weight, initial presenting symptoms at admission, final diagnosis and outcome in regards to whether the newborn was discharged after completion of treatment, discharged on request, left against medical advice, referred or expired were collected. Cases whose data were not available were excluded. Ethical clearance was taken from the institutional ethical committee before the initiation of the study.

Low birth weight was defined as birth weight less than 2500 grams $^{6}$. Prematurity as per the WHO definition was any live born baby before 37 completed weeks ${ }^{7}$. The diagnosis of neonatal sepsis and its division into suspected and culture proven sepsis were based on clinical profile, septic screen and blood culture ${ }^{8}$. Perinatal asphyxia was diagnosed based on the criteria set by the National Neonatal Forum of India and World Health Organization ${ }^{9}$ (APGAR score at one minute of 0-3 and 4-7 signifying severe and moderate birth asphyxia respectively) and hypoxic ischemic encephalopathy was classified based on Sarnat and Sarnat staging ${ }^{10}$.

Data was entered and analyzed using SPSS 17.0

\section{RESULTS}

During the study period of one year, there were 306 admissions into the NICU and nursery. Due to unavailability of record files, 27 cases were excluded and 279 were included for the study. There was a male predominance, 161 (57.7\%) male and 118 (42.3\%) female. The majority were of term gestation $(n=249,89.2 \%)$ and $30(10.8 \%)$ were preterm. Nearly all of the preterm babies $(n=22)$ were late preterms with gestational ages between $35-36$ weeks (i.e. $73 \%$ of preterms were late preterms).

Most of the admissions ( $n=208,74.6 \%$ ) occurred during the first 72 hours of life. Of these, the majority of cases were admitted within the first 24 hours $(n=173,62 \%$ of total cases). The remaining 71 neonates (25.4\%) were admitted after 72 hours of life.

The majority of neonates were born via spontaneous vaginal delivery (55.9\%). One hundred and ten (39.4\%) were born via caesarean section out of which 102 were emergency and eight were elective sections. Instrumental deliveries consisted of $4.7 \%(n=13)$.

The most common cause of neonatal admission was infection (45.9\%), followed by respiratory conditions (14.7\%), neonatal jaundice (12.5\%), perinatal asphyxia (9.3\%) prematurity/Small for gestational age (SGA) $(6.5$ $\%)$ and others (1.8\%). Twenty six newborns (9.3\%) who were admitted for observation (i.e. post instrumental delivery, a few episodes of vomiting, poor feeding) did not require admission or investigations and were transferred to mother's side within six hours (Table 1).

Out of 279 patients, blood culture was sent in 191 cases. Out of these, there were 10 positive yields (5.2\%). The organisms isolated were: coagulase negative Staphylococcus (3), Enterococcus species (3), Staphylococcus aureus (2), Klebsiella species (1) and Acinetobacter species (1).

Most neonates (244 i.e. $87.4 \%$ ) recovered and were discharged after completion of treatment. In $5.4 \%$ (15 cases), the baby was discharged at the parents' request and six (2.2\%) left against medical advice. Ten neonates (3.6\%) were referred for either surgical causes or for ventilatory support. There were a total of four mortalities (1.4\%), three of which were due to perinatal asphyxia and one was a Down's syndrome with fulminant sepsis. 
Table 1: Indications of admission into the neonatal care unit.

\begin{tabular}{|c|c|c|}
\hline Final diagnosis & $\begin{array}{l}\text { Number of cases } \\
\qquad(n=279)\end{array}$ & $\begin{array}{c}\text { Percentage of total } \\
(\%)\end{array}$ \\
\hline Infection & 128 & 45.9 \\
\hline Suspected sepsis & 103 & 36.9 \\
\hline Culture proven sepsis & 10 & 3.6 \\
\hline Septic shock & 4 & 1.4 \\
\hline Meningitis & 1 & 0.4 \\
\hline Intrauterine infections & 3 & 1.1 \\
\hline Umbilical sepsis & 1 & 0.4 \\
\hline Staphylococcal skin infection & 6 & 2.1 \\
\hline Respiratory conditions & 41 & 14.7 \\
\hline Transient tachypnea of newborn (TTN) & 20 & 7.2 \\
\hline Meconium aspiration syndrome (MAS) & 13 & 4.6 \\
\hline Pneumonia & 6 & 2.1 \\
\hline Respiratory distress syndrome (RDS) & 1 & 0.4 \\
\hline Parapertusis & 1 & 0.4 \\
\hline Neonatal jaundice & 35 & 12.5 \\
\hline Exaggerated physiological & 20 & 7.2 \\
\hline ABO incompatibility & 12 & 4.3 \\
\hline Rh incompatibility & 3 & 1.1 \\
\hline Perinatal asphyxia & 26 & 9.3 \\
\hline no HIE* & 24 & 8.6 \\
\hline HIE & 2 & 0.7 \\
\hline Observation & 26 & 9.3 \\
\hline \multicolumn{3}{|l|}{ Prematurity/Small for gestational age(SGA) } \\
\hline Prematurity + IUGR & $\begin{array}{c}18 \\
8\end{array}$ & $\begin{array}{l}6.5 \\
2.9\end{array}$ \\
\hline \multirow{2}{*}{ Prematurity alone } & 9 & 3.2 \\
\hline & 1 & 0.4 \\
\hline Surgical condition & 2 & 0.7 \\
\hline Hirschsprung disease & 1 & 0.4 \\
\hline Posterior urethral valve & 1 & 0.4 \\
\hline Dehydration fever & 2 & 0.7 \\
\hline Cold stress & 1 & 0.4 \\
\hline
\end{tabular}

*Hypoxic ischemic encephalopathy

\section{DISCUSSION}

The data retrieved during this study of 279 babies over a period of one year was comparable to other data available from within and out of the country. However, there were a few notable differences.

The leading cause of admission into the neonatal care unit at our center was infection (45.9\%), which was higher than other centres in Nepal (21.4\%-32.6\%) ${ }^{5}$. The probable cause of this is twofold. For one, what we have labelled as infection was inclusive not only of neonatal sepsis (suspected and culture proven, along with pneumonia and meningitis) but also of other forms of infections such as intrauterine infections and local infections. Secondly, more than one fourth of neonates with suspected sepsis $(28.2 \%)$ were those who were worked up in view of premature rupture of membranes (PROM) of more than 18 hours. The proportion of neonates with PROM as a risk factor who actually develop sepsis varies drastically depending on the different criteria used for the diagnosis of neonatal sepsis. In a study done in Pakistan, the incidence of culture-proven early onset neonatal sepsis following PROM was found to be as low as four percent ${ }^{11}$.

On the other hand, our rate of perinatal asphyxia (9.3\%) was much lower than others $(10 \%-22 \%)^{3,4,12,13}$. A possible reason is that emergency caesarean section was done 
as soon as fetal distress was detected thus lowering the resultant perinatal asphyxia.

The majorities (89.2\%) were term gestation and $10.8 \%$ were preterm. The bulk of the preterm babies were of gestational ages between 35-36 weeks. This finding was different from other centres where the percentages of premature babies were higher $(23.8 \% \text { to above } 50 \%)^{3-5}$. This is probably due to the fact that our center is a level two NICU were as the others are fully functional level three NICUs, and that antenatal cases in labour with gestational ages below 34 weeks were referred to higher centres.

Most of our admissions (62\%) occurred during the first 24 hours of life. Another study done in Nepal found $44.5 \%$ of admissions during the first 24 hours $^{3}$. This reemphasizes the fact that most of the neonatal problems present within the first day of life, during which early detection and intervention is crucial.

In this study, there was a male predominance with a male to female ratio of 1.4:1 versus 1.1:1 to 1.9:1 in other studies $^{3,4,14}$ suggesting that the male gender is more susceptible to illness during the neonatal period.

\section{REFERENCES}

1. Ministry of Health and Population (MOHP) [Nepal], New ERA, ICF International Inc. Nepal Demographic and Health Survey 2011. Kathmandu, Nepal: Ministry of Health and Population, New ERA, ICF International; 2012.

2. Aurangzeb B, Hameed A. Neonatal sepsis in hospitalborn babies: bacterial isolates and antibiotic susceptibility patterns. J Coll Physicians Surg Pak. 2003;13(11):629-32. Epub 2004/01/01. doi: 11.2003/ jcpsp.629632. PubMed PMID: 14700488.

3. Gauchan E, Basnet S, Koirala DP, Rao KS. Clinical profile and outcome of babies admitted to neonatal intensive care unit (NICU). J Inst Med. 2011;33(2):1-8.

4. Shah GS, Yadav S, Thapa A, Shah L. Clinical Profile and Outcome of Neonates Admitted to Neonatal Intensive Care Unit (NICU) at a Tertiary Care Centre in Eastern Nepal. J Nep Paediatr Soc. 2013;33(3):177-81.

5. Shrestha S, Karki U. Indications of admission and outcome in a newly established neonatal intensive care unit in a developing country (Nepal). Nepal Med Coll J. 2012;14(1):64-7. Epub 2013/02/28. PubMed PMID: 23441499.
There were four mortalities (1.4\%) and 10 (3.4\%) referrals during the one year period. Other centres had mortality rates that were higher $(13.7 \%-27 \%)^{3-5}$ probably due to more number of preterm babies and sicker neonates.

The limitations of this study are mainly that this hospital based study which cannot be generalized to the entire population and that this study is urban based and the results may not be comparable to rural population.

\section{CONCLUSION}

In this study at a level two NICU, infection was the leading cause of admission into the neonatal care unit, followed by respiratory conditions. Unlike other centres, perinatal asphyxia and prematurity/ LBW were not as significant. Majority of the admissions occurred within the first 24 hours of life. Therefore to improve neonatal outcome, it is imperative to be vigilant especially during the first 24 hours of life. Progress is possible, but only if we manage to prevent or detect and treat problems as early as possible, which can be achieved by public awareness, training of manpower and procurement of necessary equipments.

6. United Nations International Children's Emergency Fund, World Health Organization. Low Birthweight: Country,regional and global estimates [Internet]. UNICEF, WHO; 2004 [cited 2014 Nov 10]. Available from: http://www.unicef.org/publications/files/low_ birthweight_from_EY.pdf.

7. World Health Organisation. Fact sheet 2014 [Internet]. Geneva: WHO; 2014 [cited 2014 Nov 10]. Available from: http://www.who.int/mediacentre/ factsheets/fs363/en/.

8. Polin RA. Management of neonates with suspected or proven early-onset bacterial sepsis. Pediatrics. 2012;129(5):1006-15. Epub 2012/05/02. doi: 10.1542/ peds.2012-0541. PubMed PMID: 22547779.

9. National Neonatology Forum of India. Teaching Aids on Newborn Care:Post Asphyxia Management [Internet]. New Delhi: National Neonatology Forum of India; [cited 2014 Nov 10]. Available from: http:// www.newbornwhocc.org/pdf/teaching-aids/ postasphyxia.pdf.

10. Sarnat HB, Sarnat MS. Neonatal encephalopathy following fetal distress. A clinical and electroencephalographic study. Arch Neurol. 1976;33(10):696-705. Epub 1976/10/01. PubMed PMID: 987769. 
11. Alam MM, Saleem AF, Shaikh AS, Munir O, Qadir M. Neonatal sepsis following prolonged rupture of membranes in a tertiary care hospital in Karachi, Pakistan. J Infect Dev Ctries. 2014;8(1):67-73. Epub 2014/01/16. doi: 10.3855/jidc.3136. PubMed PMID: 24423714.

12. Omoigberale Al, Sadoh WE, Nwaneri DU. A 4 year review of neonatal outcome at the University of Benin Teaching Hospital, Benin City. Niger J Clin
Pract. 2010;13(3):321-5. Epub 2010/09/23. PubMed PMID: 20857794.

13. Begum T, Islam MR. Clinical profile and outcome of 100 neonates in perspectives of neonatal care in a tertiary hospital. J Shaheed Suhrawardy Med Coll. 2012;2(1):2-3.

14. Simiyu DE. Morbidity and mortality of neonates admitted in general paediatric wards at Kenyatta National Hospital. East Afr Med J. 2003;80(12):611-6. Epub 2004/03/17. PubMed PMID: 15018416. 